\title{
Revisión
}
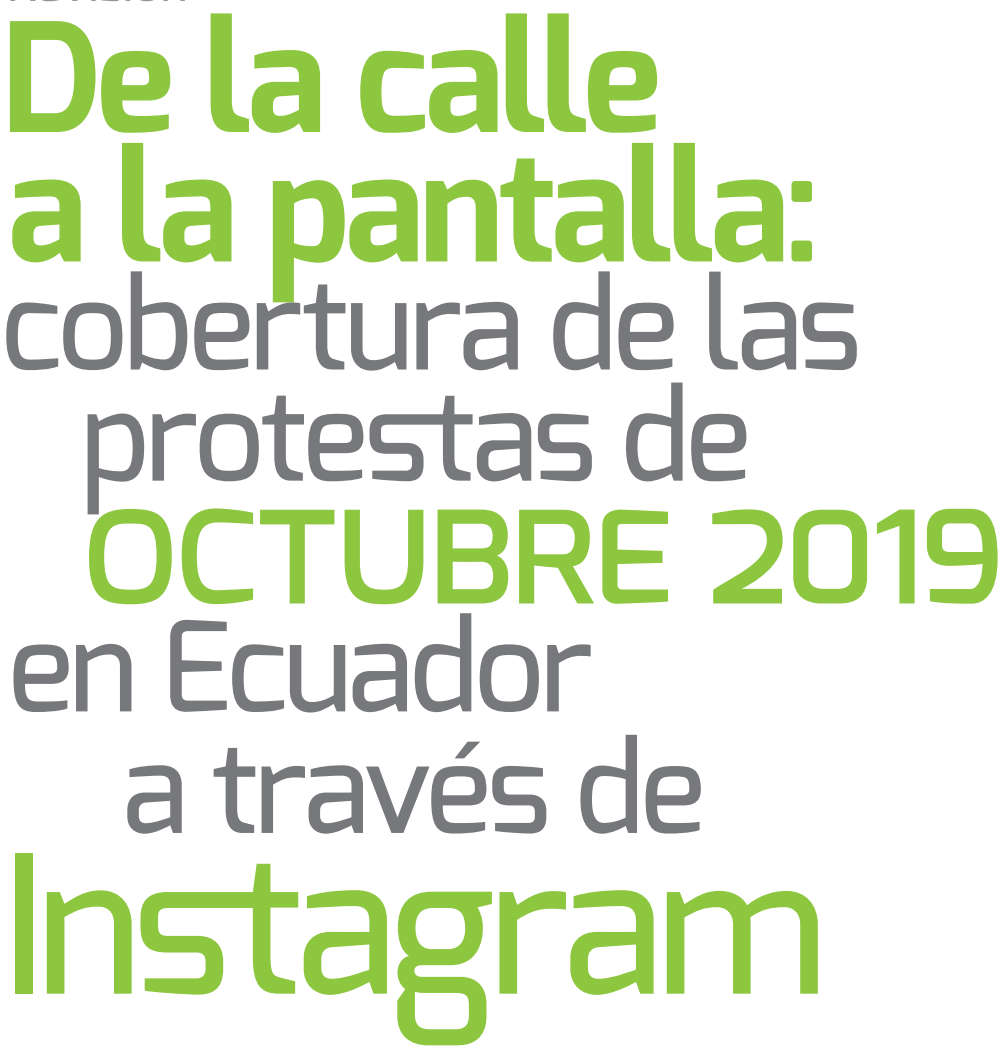

\section{Melissa Clavijo}

melissaclavijonaula国gmail.com

Recibido: 29 de agosto de 2020 | Aceptado: 10 de septiembre de 2020

DOI: https://doi.org/10.18272/pd.v4i1.1974

Referencia de este artículo:

Clavijo, M. (2020). De la calle a la pantalla: cobertura de las protestas de octubre 2019 en Ecuador a través de Instagram. \#PerDebate, volumen 4 (pp. 298-313). Quito: USFQ Press.

Melissa Clavijo es licenciada en Periodismo por la Universidad San Francisco de Quito. Locutora y productora digital de radio Forever, también es investigadora del OIME. Inició su carrera profesional con pasantías en el Grupos Ekos y el programa Visión 360 de Ecuavisa. 


\section{Resumen}

Esta investigación analizó la cobertura sobre el paro nacional de octubre 2019 en Ecuador que realizaron GK y La Posta, dos medios nativos digitales, en sus cuentas de Instagram. Por medio de un estudio cualitativo y cuantitativo, se descubrió que adaptaron su contenido para que sea independiente e informativo. Los formatos que Instagram ofrece son amigables para los medios en cuestión y jugaron un rol primordial en cómo estos cubrieron este hecho social.

\section{Palabras clave}

protestas, redes sociales, cobertura digital, audiencias, Instagram

\section{From the Street to the Screen: Coverage of the October 2019 Protests in Ecuador Through Instagram}

\section{Abstract}

This research analyzed the coverage of the October 2019 national strike in Ecuador by GK and La Posta, two digital native media, on their Instagram accounts. Through a qualitative and quantitative study, it was found that they adapted their content to be independent and informative. The formats that Instagram offers are friendly to digital media and played a key role in how these covered this social fact.

\section{Keywords}

protests, social media, digital coverage, audience, Instagram 


\section{Introducción}

En redes sociales fluye infoentretenimiento sobre hechos económicos, culturales, sociales y políticos. La cobertura en tiempo real de los acontecimientos mundiales responde al estilo de vida que lleva una sociedad adicta a la inmediatez. Por ello, las movilizaciones ciudadanas ya no sólo se sienten en las calles sino en la pantalla de un teléfono. Las redes sociales tienen una gran fuerza cuando se trata de intervenir con acciones en lo político, social, ético, cultural, artístico mediante el impulso colectivo de agitación y propuesta de cambio (Ojeda, Grandio y Joan, 2012). No es coincidencia que la cobertura mediática de protestas se vincule estrechamente con las tendencias en Internet. El 40\% de los internautas usan plataformas digitales para mantenerse informados de eventos en tiempo real y noticias (GlobalWeblndex, 2019). Esto supone que la digitalización y la convergencia han abierto camino a una nueva mutación en la esfera comunicativa.

Una transformación que se puede abordar desde la aceleración en la circulación de las noticias, el aumento del número de actores participantes en la producción de información y el cambio en la relación que se establece entre medios y público. (Gonzales-Molina y Ramos Del Cano, 2014, p. 38)

La nueva relación entre medios y público se palpó en Ecuador durante las protestas sociales de 2005 con la caída de Lucio Gutiérrez. Todo inició con una emisora que abrió sus micrófonos al público, radio La Luna. Un civil convocaba a sus compañeros ecuatorianos a realizar un "cacerolazo", símbolo conocido en la región latinoamericana para mostrar inconformidad colectiva. Dicha convocatoria junto a miles de mensajes de texto, le dio paso a manifestaciones a partir del 13 de abril de 2005 (De la Torre, 2008). Para el 20 de abril de 2005 la situación, en palabras del Comando Conjunto de las Fuerzas Armadas, era insostenible. Y, según la institución, para evitar el derramamiento de sangre, retiraron su apoyo al presidente que poco antes había sido cesado en sus funciones por una nueva mayoría del Congreso. Para De la Torre (2008), los medios de comunicación ejercieron presión mostrando el descontento popular. Sin embargo, Gustavo Abad (2011) ofrece una visión mucho más crítica sobre el trabajo de los medios de comunicación conocidos actualmente como tradicionales: televisión, radio y prensa.

Alineados con un discurso de estabilidad y orden social promovido desde el poder (...) estos medios dieron la espalda a los manifestantes, quienes, al no verse representados, dejaron de creer en ellos y buscaron otros medios, menos grandes y tradicionales, pero sensibles a sus demandas. (p. 17)

Pone como ejemplo al diario El Universo, periódico que colocó en primera plana una foto de media página del Papa Benedicto XVI, mientras ese 19 de abril las manifestaciones ascendían a cerca de 100 mil protestantes que se diri- 
gían al centro histórico de Quito. Solo en una nota secundaria sin fotografía se publicó: "Gobierno organiza marchas; Moncayo declara emergencia".

Se entiende entonces por qué la gente, durante esos días, confiaba más en los mensajes de boca en boca, por correo electrónico y por celular para informarse de lo que pasaba. El éxito de la auto convocatoria se debió, en gran medida, a que fue asumida como una declaración de independencia ciudadana respecto de los partidos políticos y de los medios de comunicación tradicionales. (Abad, 2011, pp. 18 -19)

Dicha falta de representación, expuesta por Abad, se palpa día a día con la diversidad de medios de comunicación que surgieron a raíz de la revolución del Internet. Tal fue el cambio de dinámicas que surgió el término periodismo ciudadano, entendido como la actividad de gente común enfocada en la difusión pública de información a través de herramientas como blogs o redes sociales. Lo que antes se publicaba escuetamente y con difícil difusión en páginas web personales, hoy está a la mano de miles de internautas por medio de plataformas digitales como Instagram, Facebook y Twitter. En un caso de estudio sobre el comportamiento de medios de comunicación en Twitter durante el terremoto de 2016 en Ecuador, Diana Rivera y Claudia Rodríguez citan a Dan Gilmour (2016), quien explica que el periodismo está sufriendo una metamorfosis profunda en su estructura, que hoy se evidencia con la participación ciudadana en redes sociales ya que estas se han convertido en una herramienta perfecta para mantener una comunicación continúa basada en la interactividad (Hernández y Ramón, 2010).

El paro nacional de octubre de 2019 fue una de las mayores movilizaciones civiles del país, pues representó el cierre de un $15 \%$ de las vías de la capital y una pérdida económica de 1457 millones de dólares. El jueves 3 de octubre de 2019, por el Decreto 883, dejaron de aplicarse los subsidios al diésel y a las gasolinas extra y ecopaís en Ecuador tras 45 años de vigencia como mecanismo para cubrir parte de la brecha fiscal y reducir el endeudamiento público. Gremios de transportistas, colectivos estudiantiles y, especialmente, el movimiento indígena rechazaron la medida con un paro nacional que duró 12 días hasta la derogatoria del decreto el domingo 13 de octubre.

La Comisión Interamericana de Derechos Humanos (2020), CIDH, emitió un informe sobre las acciones violentas en contra de los agentes del Estado, como el disparo de armas caseras y bombas incendiarias, el secuestro de más de 400 agentes de la fuerza pública — que incluye denuncias de violencia sexual contra policías mujeres, apedreamiento de ambulancias y obstaculización a los bomberos, y otras más. En el informe también se mencionan las pérdidas económicas de varios sectores productivos, los saqueos y los ataques a edificios e instituciones. 
Entre las recomendaciones, la CIDH pide respeto y garantía del derecho a la protesta, a la libertad de expresión, a la reunión pacífica y a la participación política de la población. Además, recomienda que se capacite a los encargados de mantener el orden público en materias de derechos humanos e interculturalidad, con la participación de las organizaciones indígenas. Dentro de las agresiones, se registraron también 127 periodistas agredidos y alrededor de 60 medios de comunicación afectados. Entre ellos estuvieron medios de distintos formatos como radio, prensa, televisión y web (GK, 2020).

El reto que enfrentan los medios digitales durante protestas sociales ya no es solo el del campo, sino que compiten con el flujo de información mientras se adaptan a cada red social en la que difunden su contenido. El paro nacional de octubre fue un fenómeno sin precedentes en la historia ecuatoriana. Tuvo una presencia en redes de tal magnitud que hubo personas que vieron las cadenas nacionales a través de sus cuentas de Facebook e, incluso, compartían en vivo, por medio de sus cuentas de Instagram, lo que ocurría desde sus hogares o ciudades. La difusión de información fue primordialmente audiovisual. Videos de saqueos, calles cerradas y protestas ahondaron los celulares de los ecuatorianos desde todo tipo de perspectivas.

Después de la compra que hizo Facebook de Instagram en 2012 por la cantidad de 1000 millones de dólares (Caerols, Tapia y Carretero, 2013), Instagram se ha convertido en una de las redes sociales más influyentes en el mundo con 1 billón de usuarios mensuales (Newberry, 2019). Instagram es una red social esencialmente visual y móvil que favorece en su diseño de interacción la percepción de movilidad, instantaneidad y autenticidad en la comunicación visual (Selva-Ruíz y Caro-Castaño, 2017). En 2018 fue la aplicación más descargada después de YouTube. Esta plataforma presenta un perfil de usuario marcadamente joven. El $90 \%$ de sus usuarios tiene menos de 35 años y en ella se comparte una media de 95 millones de fotografías y vídeos diarios (Newberry, 2019). ¿Cómo crearon contenido especializado en esta plataforma? ¿Cómo trabajaron los medios el flujo de información? ¿Cómo la procesaron? Esta investigación tiene como objetivo analizar la cobertura de dos medios nativos digitales durante el paro nacional de octubre.

\section{Metodología}

Esta investigación utilizará el método del análisis de contenido como recurso de estudio cuantitativo y descriptivo, como lo describe Berelson (1952), por ser "una técnica de investigación para la descripción objetiva, sistemática y cuantitativa del contenido manifiesto de la comunicación" (Rodrigo, 1999. p. 104). El contenido analizado serán las publicaciones de Instagram de dos medios nativos digitales ecuatorianos: GK y La Posta. 
Para proceder el análisis digital de estos dos medios, es importante definir la línea editorial de cada uno. GK nació en 2014 como un blog para publicaciones de personas de diferentes perfiles profesionales. Evolucionó hasta convertirse en un medio de comunicación, cuyo fuerte es el periodismo narrativo enfocado en temas de género, política, pero, primordialmente, derechos humanos. Dentro de sus plataformas actuales, están un sitio web y cuentas de Instagram, Twitter, Facebook y YouTube. La Posta fue fundada en 2017 bajo el eslogan "la noticia, pero más sexy", con la premisa de mostrar contenido sobre política con un vocabulario satírico y entretenido. Al inicio, cumplieron con el requisito de tener un sitio web, sin embargo, cambiaron su estrategia y migraron únicamente a redes sociales. Su sitio web quedó como una carta de presentación al mundo que más bien redirecciona a quien la abre a sus otras plataformas digitales.
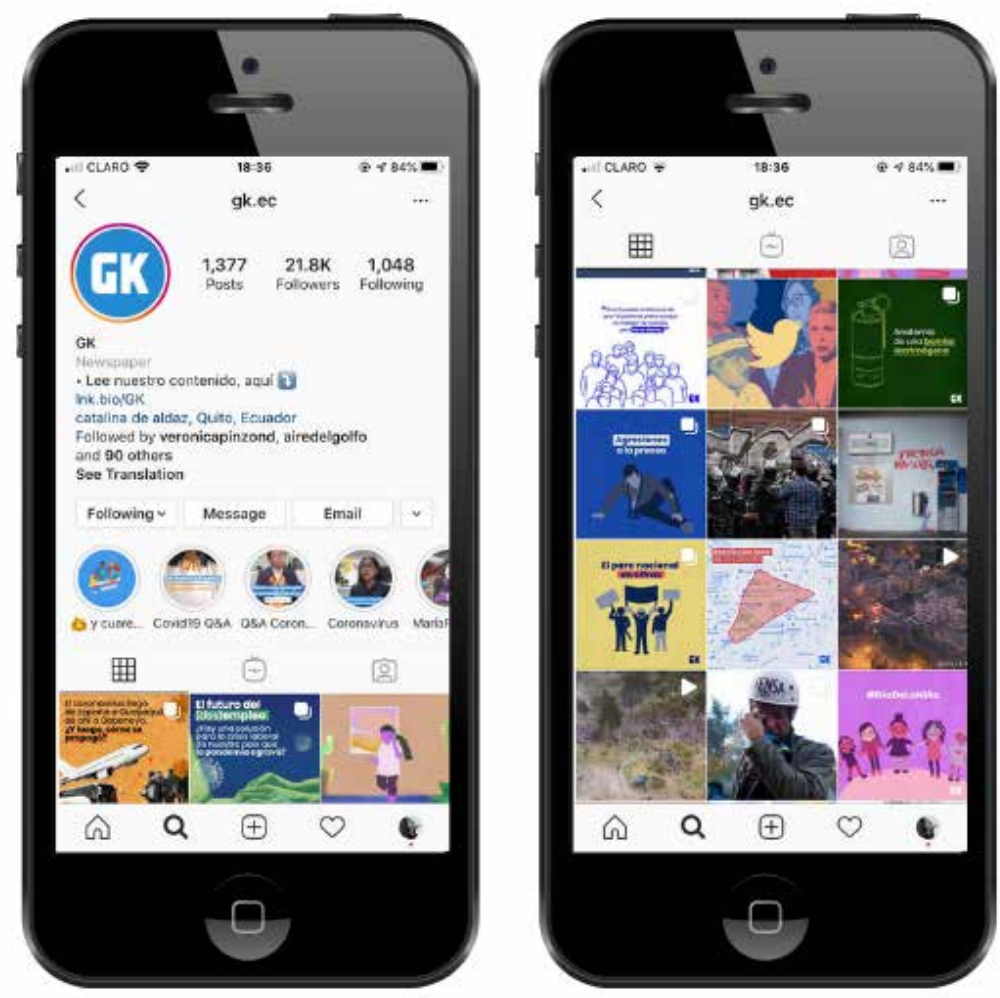

Captura de pantalla de la cuenta de GK en Instagram y sus publicaciones de octubre de 2019.

Instagram es una plataforma que permite a sus usuarios crear y consumir diversos productos audiovisuales. Dentro de sus características, está el aplicar efectos al contenido subido e incluso darle la opción de diseñar sus propias 
decoraciones. Los dos formatos audiovisuales principales son foto y video. Estos se usan en tres grandes opciones de la red social: publicaciones, videos de Instagram TV, historias y transmisiones en vivo. Las publicaciones pueden contener una o más fotos (opción conocida como carrusel de fotos) o un video de máximo un minuto de duración. Esta publicación o post va acompañada de una descripción que no tiene límite de caracteres. Los videos que sobrepasan el límite de un minuto pueden colocarse en la sección IGTV, siglas que hacen referencia a portales como YouTube. Esta sección aparece en una viñeta en el perfil del usuario. También existe la opción de que lo publicado se muestre en la sección principal de fotos o videos. Las historias de Instagram son videos de no más de 15 segundos que se suben en formato 16:9 y quedan 24 horas en el perfil del usuario. Los videos en vivo también se transmiten en 16:9. Estos permiten usar la cámara frontal y trasera del teléfono, unir a otro usuario a la transmisión, tener una sección de preguntas e ingresar fotos del carrete o la galería del usuario, mientras transcurre el programa.
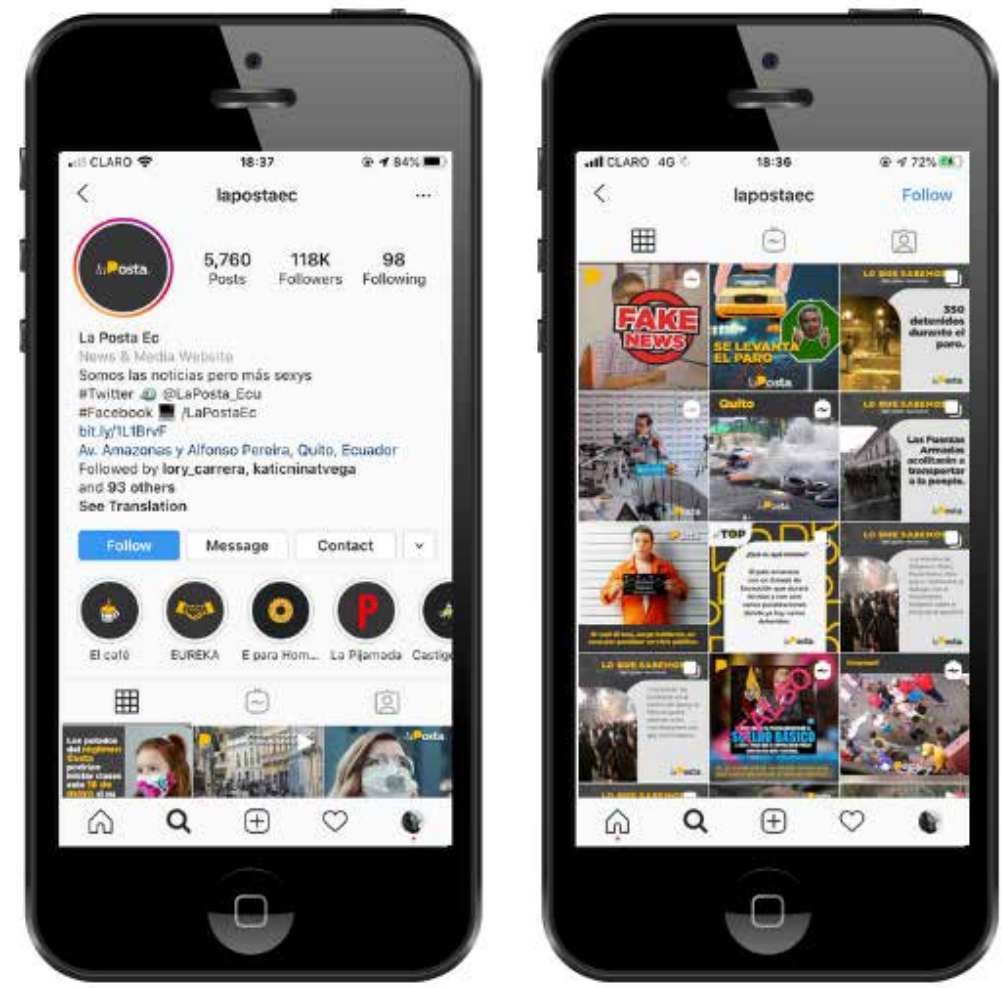

Captura de pantalla de la cuenta de La Posta en Instagram y sus publicaciones de octubre de 2019. 
En esta investigación se tomará únicamente como referencia a las publicaciones de fotos y videos que aparezcan en la sección principal del usuario de cada medio porque es el único producto que se mantiene con el paso del tiempo y con la indicación de la fecha en que fue publicado. Se seleccionarán las publicaciones del 3 al 15 de octubre, lapso en el que la coyuntura nacional se enfocó en los acontecimientos del paro nacional.

Para analizar el contenido publicado en las cuentas de Instagram de cada medio, se tomará como referencia el método de Valor Agregado Periodístico, el cual estudia el contenido mediático basado en una guía de variables alrededor del proceso de selección y creación, enfocados en la medición de calidad de un producto periodístico. En este caso particular en el que el producto no contiene los elementos clásicos del periodismo, se adaptarán las variables para que coincidan con la efectividad de difusión en Instagram y ejes de la profesión tales como la veracidad de información.

Desde el aspecto periodístico se evaluará el uso de material propio para la cobertura del paro nacional. Con esto se cuantificarán las publicaciones que usaron como fuentes las redes sociales o si pertenecen a la reportería de cada medio. En lo que tiene que ver con elementos de la red social, específicamente será el uso de hashtags y el tipo de material audiovisual utilizado: foto, video o ilustración. De esta manera, se analizará la cobertura de protestas, se entenderá cuál fue el proceso hasta llegar a la publicación y el método para planificar que prima en los sujetos de investigación.

Para GK deberá agregarse una variable extra: qué material se promocionó en cada publicación ya que este medio utiliza sus redes para guiar a sus seguidores hacia su sitio web, en el que se presenta contenido de largo aliento. La Posta, como ya se mencionó, trabaja de manera invertida. Una vez recolectada y procesada la información, se hicieron entrevistas con representantes de cada medio que tengan injerencia directa con el proceso de publicación en Instagram: Jenny Navarro, coordinadora de redacción de La Posta, y a Verónica Aumala, editora de audiencias de GK.

Este sistema fue creado por un equipo de investigación de la Universidad Católica de Chile junto con las sedes en Argentina, Sabana, Colombia y Perú. Con esta adaptación, se podrá delimitar ciertos estándares claves para la adecuada "transmisión de hechos desde la realidad percibida por el periodista hacia el público que requiere tener acceso a ellos para actuar y opinar" (Pellegrini, Puente, Porath, Mujica y Grassau, 2011, p.25). 


\section{Resultados}

Entre el 3 y el 15 de octubre de 2019, GK y La Posta cubrieron en Instagram los eventos del paro nacional que vivió el Ecuador. No se estudiaron las publicaciones desde el 1 de octubre porque, si bien en aquella fecha se anunciaron las medidas económicas que dieron pie al paro nacional, fue a partir del 3 de octubre que se reportaron protestas por parte de la ciudadanía, específicamente del gremio de transportistas. Dentro de las cuatro aristas analizadas, la primera fue el número de publicaciones en Instagram por día detallada en la Figura 1.

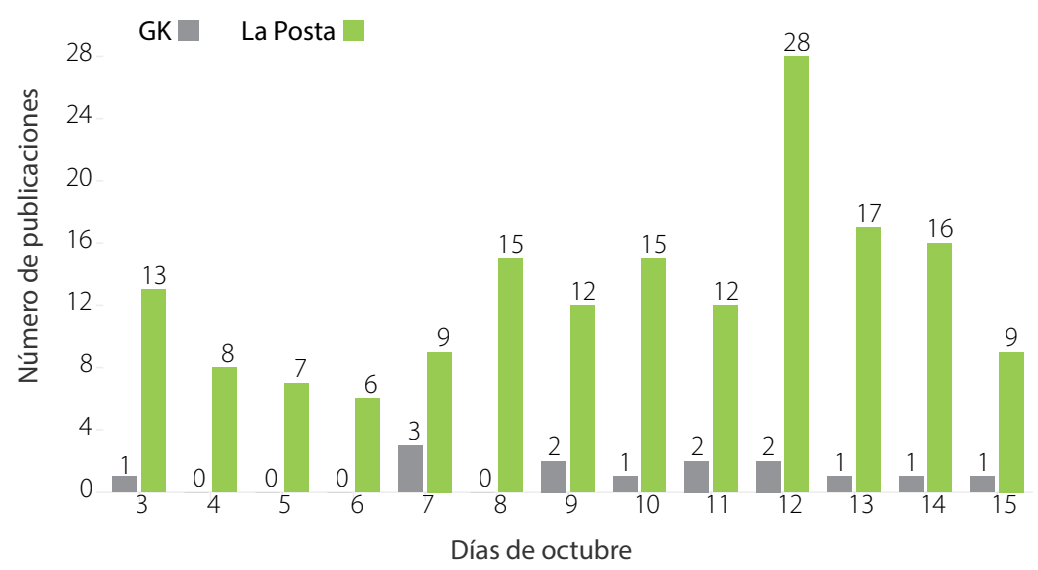

Figura 1. Publicaciones entre el 3 y 15 de octubre. Elaboración propia.

La Posta registró 167 publicaciones en total entre el 3 y 15 de octubre. GK presentó una cantidad mucho menor: 14 publicaciones en dicho intervalo de tiempo. Esta diferenciación se debe a que GK tiene un sitio web en el que colgó 49 reportajes durante las fechas estudiadas. Ninguno de los dos medios se enfocó en cubrir hard news, pero dado el contexto nacional decidieron volcar su atención en los eventos diarios. GK realizó infografías que dieron pie a que se continúe leyendo los reportajes de largo aliento, mientras que La Posta basó su cobertura en videos y pastillas informativas.

La fecha con más movimiento para La Posta fue el 12 de octubre, día en el que se reportaron saqueos en el edificio de la Contraloría General del Estado y un ataque vandálico a las instalaciones del canal de televisión Teleamazonas. Asimismo, fue el día en el que la Confederación de Nacionalidades Indígenas del Ecuador (CONAIE), Leonidas Iza, dirigente principal de las protestas, anunció que accedía al diálogo con el gobierno de Lenin Moreno.

Aunque hubo días en los que GK no publicó nada, Verónica Aumala (2020), editora de audiencias de GK, aseguró que sí subieron fotos o videos que sus 
reporteros obtuvieron en la calle en el formato historias de Instagram o transmisión en vivo. Dicho producto duró 24 horas, pero lo ubicaron como destacado en su perfil y lo añadieron como sección en su sitio web.

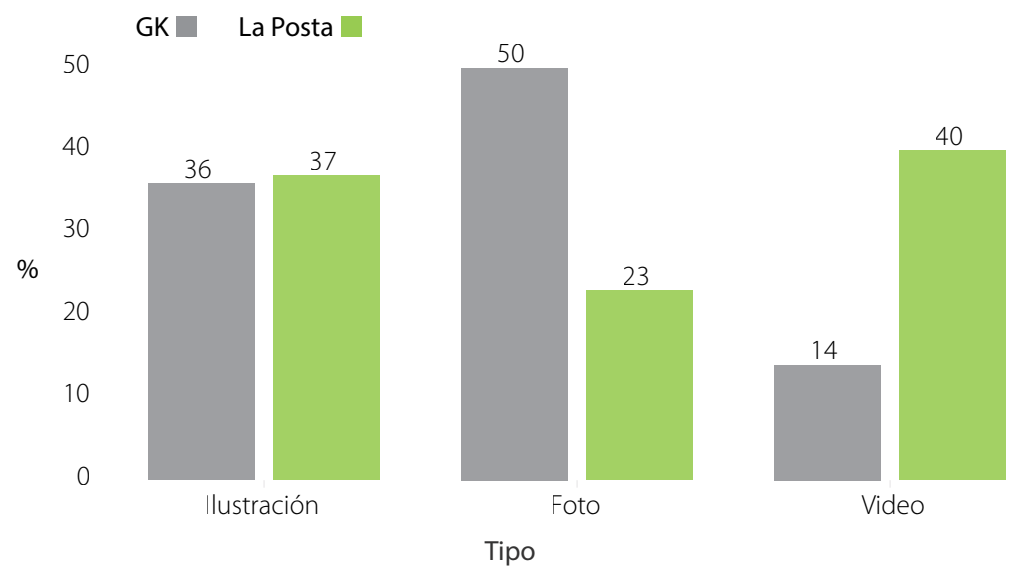

Figura 2. Tipo de formato audiovisual del material gráfico. Elaboración propia.

Con respecto al tipo de material que usaron, se clasifica en foto, video o ilustración. Como se ve en la Figura 4, GK concentró la mayoría de sus publicaciones en fotos (50\%). Estas fueron específicamente sobre las manifestaciones y marchas del paro nacional y pusieron como personaje principal a los protestantes. Cada publicación con fotografía iba acompañada de una descripción narrativa que, según Aumala, era redactada por el periodista que estaba en el campo para dar cobertura de largo alcance que hacían en su sitio. A esto le siguieron las ilustraciones (36 \%) con propósito infográfico que destacaban cifras sobre el paro nacional. A diferencia de las publicaciones con fotos, estas no contaban con una descripción narrativa sino con la promoción de la cobertura en el sitio web. Finalmente, los videos (14\%) publicados durante esta cobertura también iban acompañados de un texto narrativo sobre aquel día y la promoción de productos más allá de la red social.

La Posta en cambio dio énfasis a su contenido audiovisual (40 \%) y compartió videos difundidos en redes sociales, columnas de opinión y análisis sobre los hechos del paro nacional desde perspectivas económicas y políticas. Este formato es común en el contenido del medio puesto que la mayoría de sus productos son programas de entrevistas, cápsulas de información en video o segmentos como Economía para Homero. Sin embargo, sus ilustraciones (37\%) no se quedaron atrás puesto que el medio tiene dos segmentos principales en ilustración: \#elTop y \#LoQueSabemos. Jenny Navarro (2020), coordinadora de redacción, explicó: 
\#elTop es como la portada de un periódico. Es el titular del periódico, entonces desarrollamos esa noticia todos los días. \#LoQueSabemos nace porque necesitábamos cubrir un tema rápido. Es lo que la gente quiere. Quieren tener la idea sobre lo que está pasando en algún suceso y, si nos demoramos, tal vez esa noticia la revisarán en El Comercio o en El Universo.

\#elTop responde a las preguntas básicas de ¿qué?, ¿cómo?, ¿cuándo?, ¿dónde? y ¿quién?, conocidas también como las 5 w por su traducción al inglés. \#LoQueSabemos es una especie de flash informativo ilustrado con viñetas de datos.

Las fotos de La Posta sobre las manifestaciones destacaron el ambiente en las calles y el daño a la propiedad pública. Sin embargo, dentro de las fotos incluyeron comunicados de entidades públicas y privadas. Lo común es ver esta información procesada por el medio, pero La Posta subió directamente las imágenes de los comunicados. "El nivel de noticias que salían por minuto era abrumador. Era imposible de manejar. Entonces creo que la gente valoraba mucho que estemos informando minuto a minuto", argumentó Navarro (2020).

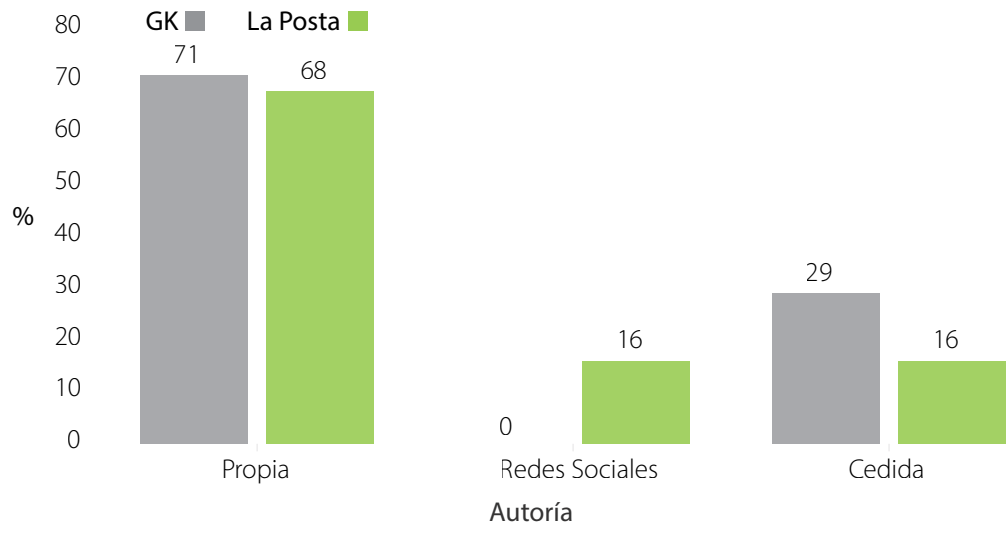

Figura 3. Material publicado clasificado por autoría. Elaboración propia.

GK no utilizó ningún material de redes sociales. El 71 \% es de su autoría y para el resto dio crédito a fotógrafos freelancers o agencias a las cuales compraron el material. La Posta tiene $16 \%$ de material obtenido de redes sociales sin dar crédito a las cuentas de donde lo obtuvieron. Navarro (2020) explicó que ciertas publicaciones suelen ser denuncias y sus fuentes solicitan no figurar en los créditos. Los medios estudiados tienen distintos protocolos para la verificación de información específicamente del tipo proveniente de redes sociales. “Para nosotros es muy importante publicar contenido que sea realmente verificado. Quita mucho esfuerzo y no somos un equipo tan grande. No es nuestra política lanzar contenido para ganar más y más likes", explicó Aumala (2020) para GK. 
Por otro lado, Navarro (2020) dijo que La Posta confía mucho en la verificación de sus fuentes, pero reconoció que depende de la situación. Explicó lo siguiente al hablar de su porcentaje de contenido proveniente de redes sociales.

Como toda noticia, sea denuncia o sea algo que vemos en Twitter, seguimos el principio básico de verificación: quién lo publicó, ir a la fuente. Si lo encontramos en la cuenta de Twitter de algún prefecto, por ejemplo, está bien porque actualmente estas cuentas son fuentes. También puede pasar que esa fuente fiable no pudo haber investigado. En ese sentido, hay que prestar atención. (Navarro, 2020)
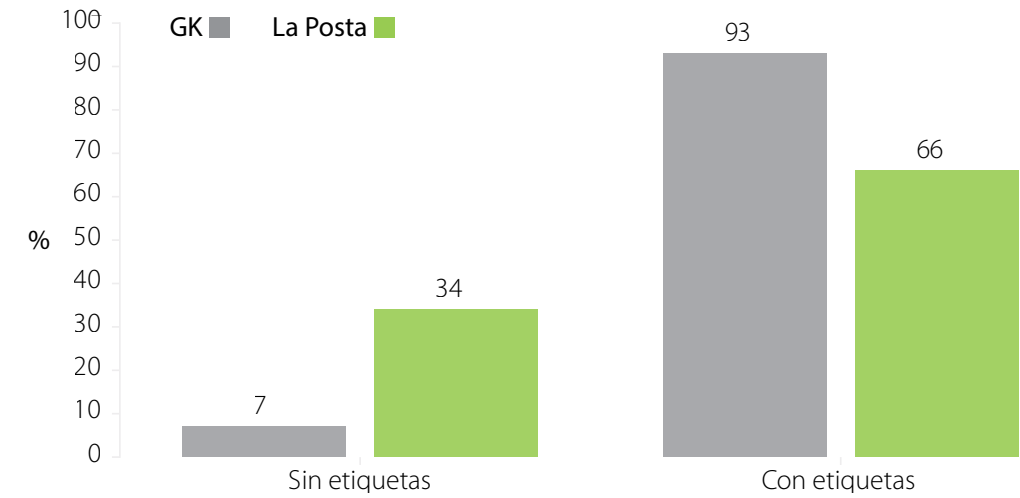

Figura 4. Utilización de etiquetas o hashtags. Elaboración propia.

El uso de etiquetas giró en torno al paro nacional en Ecuador. Estas constan en la mayoría de publicaciones de ambos medios. La Posta utilizó hashtags más específicos sobre los segmentos de su medio o sobre a quiénes iban a entrevistar. Sus descripciones fueron cortas, de una oración. Navarro (2020) dijo que, según la experiencia que tienen, las personas comparten el contenido de la fotografía o video, más de lo escrito en la descripción. Respecto a los hashtags, GK se enfocó en lo general: la ubicación de la foto y la etnia o profesión de quienes aparecían en las imágenes. Las descripciones de las fotos y videos fueron de larga extensión. Aumala (2020) aseguró que ellos han palpado buenos resultados de su estilo narrativo en sus redes. Instagram es una red social con pocos niveles de convertibilidad, es decir, es muy complicado que un usuario migre hacia una página web desde la aplicación. "Por lo que, producimos mucho contenido en Instagram que, de cierta forma, te resuma la información que hay en la web y que aprendas algo de verdad, aunque no lo hayas leído por completo" (Aumala, 2020).

Durante el paro nacional ambos medios publicaron material no relacionado a la temática. En el caso de La Posta, lanzó un segmento en video sobre recomen- 
daciones de películas y versiones de \#elTop que contaban historias alrededor de temas culturales. "Creemos que debemos cuidar y cumplir con el ciclo informativo, sin descuidar el lado de entretenimiento, porque esa es la razón por la que la gente nos busca", alegó Navarro (2020). De igual manera, GK conmemoró el Día de la Niña por medio de un segmento llamado Hablemos de niñas, dedicado al enfoque de género de temas sociales."Siempre hay que cubrir lo coyuntural, pero no es que nosotros tenemos un equipo de noticias. Hablemos de niñas es una de las coberturas que más esfuerzos le ha representado a GK, no podíamos evitar el Día de la Niña, pese a la coyuntura. En esas épocas que hay conflictos, como hoy con la COVID-19 o en ese entonces con el paro, no podemos dejar de lado otros temas por la emergencia" (Aumala, 2020).

Estos medios nativos digitales, a pesar de tener líneas editoriales distintas, coinciden en ajustar su contenido para ser publicado en Instagram, red social que ambos entienden como una plataforma sólida y eficiente para proveer información o promocionar sus productos periodísticos.

\section{Conclusiones}

El paro nacional fue un hecho transcendental para el Ecuador en términos de movilización y organización civil que pasará a la historia. Este hecho impuso retos en distintos sectores de la sociedad. Desde el periodismo, todos los medios de comunicación tuvieron que sobrellevar cierta cantidad de desafíos para cumplir con el objetivo de informar a la ciudadanía. La cobertura de protestas ciudadanas requiere de destrezas físicas tales como de logística y organización, sin embargo, según lo analizado, las dos principales exigencias fueron el cumplimiento de la inmediatez y la verificación de datos. Dichas características son difíciles de cumplir con equipos de poco personal como en medios nativos digitales, pero no imposible.

GK y La Posta son medios de comunicación relativamente nuevos en comparación con otros de gran trayectoria. Desde su trinchera, han manejado el contenido de sus redes sociales con pocos recursos económicos y humanos. Durante el paro nacional La Posta le dio valor a la rapidez con la cual procesaban e impartían la información. Al ser un medio únicamente de redes sociales, se entiende que quienes los siguen esperan de ellos esa característica. GK, por otro lado, le dio más peso a la contextualización y verificación de datos del hecho en cuestión, lo que le restó tiempo para lograr equipararse a la velocidad con la que otros medios publicaban la información.

Dentro de las nuevas narrativas, se destaca el trabajo sectorizado que estos dos medios digitales realizan. El público decidió cómo se va a proyectar la información, eso quedó claro en el análisis cuantitativo y cualitativo. En este 
último, ambas representantes de los medios destacaron en las entrevistas que su audiencia en Instagram es millenial. A pesar de que GK tiene un sitio web en el que publica contenido de largo aliento, el medio comprende que el formato de Instagram debe ser personalizado y diferente, algo que La Posta reafirma en todo el manejo de su contenido. Es destacable el hecho de que en GK ya existe la incorporación de un puesto de trabajo que se dedica únicamente al análisis de sus audiencias.

GK y La Posta definieron una línea editorial y un nicho en cuanto a los temas que cubren. Esta tendencia de trabajar con temas muy específicos responde a la oleada de información que trajo consigo la revolución del Internet. Por ello, La Posta calificó de agobiante a la cantidad de información que recibían por minuto y GK decidió enfocarse en áreas más fácilmente verificables. En la actualidad, las audiencias prefieren escoger entre varios usuarios que les ofrezcan contenido distintivo. Por ello, estos medios de comunicación no dejaron de lado sus ejes transversales como lo son los derechos humanos y enfoques de género para GK y la sátira política y entretenimiento para La Posta.

Los medios de comunicación actualmente deben adaptarse a las nuevas narrativas y formatos que las redes sociales ofrecen. Instagram es una red social en la que la noticia o la información debe ser entregada directamente en los post mas no tratar de dirigir a la audiencia hacia otro portal. GK y La Posta desarrollan contenido que va acorde con los parámetros que la plataforma demanda de sus usuarios: tamaño y duración de fotos, videos y transmisiones en vivo. Los medios en cuestión tuvieron como objetivo que sus publicaciones contengan información independiente que no necesite de más contexto. La Posta debido a que así se maneja toda su producción y GK porque, a pesar de que necesitaba dar un "abreboca" del reportaje de largo alcance, sabía que lo más probable es que su audiencia se quedara con la información resumida. De todas formas, en ambas situaciones el producto final tenía que ser informativo y compartible.

La información impartida por medios digitales en sus redes sociales debe cumplir con los mismos parámetros de cualquier otro medio tradicional. Al final, el trabajo periodístico es el mismo y se deben cumplir con los parámetros deontológicos de la profesión. Por ello, tenemos a medios innovadores en su contenido como La Posta y GK, que tienen como base el espíritu periodístico de contar historias. Sin embargo, es innegable que el periodista ya no actúa solo o bajo los intereses que él considere importantes. La nueva era digital le da espacio a las audiencias y las redes sociales para delimitar el formato en el cual la información debe ser impartida para lograr una exitosa difusión. 


\section{Referencias}

Abad, G. (2011). Club de la pelea: gobierno y medios, un entramado de fuerzas y debilidades. Quito: Ciespal.

Caerols, R., Tapia, A., y Carretero, A. (2013). Instagram, la imagen como soporte de discurso comunicativo participado. Revista de Comunicación Vivat Academia, (124), 68-78. doi: 10.15178/va.2013.124.68-78

Comisión Interamericana de Derechos Humanos. (14 de enero de 2020). CIDH Presenta observaciones de su visita a Ecuador. Recuperado de https:// www.oas.org/es/cidh/prensa/comunicados/2020/008.asp

De la Torre, C. (2008). Protesta y democracia en Ecuador: la caída de Lucio Gutiérrez. Buenos Aires: CLACSO.

Endara, L. (1998). El marciano de la esquina: imagen del indio en la prensa ecuatoriana durante el levantamiento de 1990. Quito: Abya-Yala.

GK. (15 de enero de 2020). La CIDH presentó su informe sobre el paro. Recuperado de https://gk.city/2019/12/12/comision-multipartidista-informe-paro-asamblea/

GlobalWeblndex. (2019). GlobalWeblndex's flagship report on the latest trends in social media. Recuperado de https://www.globalwebindex.com/reports/ social-2019

Gonzales-Molina, S. y Ramos Del Cano, F. (2014). Las redes sociales en el ámbito periodístico: ¿cómo usan los medios europeos de referencia sus perfiles en Twitter y Facebook? Revista interdisciplinar de Ciencias de la Comunicación y Humanidades, (10), 38-52.

Hérnandez, A., y Ramón, F. (2010). La ventaja competitiva de las marcas tras su presencia en las redes sociales. Revista Aranzadi de Derecho y Nuevas Tecnologías, (24),19-45.

Newberry, C. (22 de octubre de 2019). 37 Instagram Stats That Matter to Marketers in 2020. Recuperado de https://blog.hootsuite.com/instagram-statistics/

Ojeda, M., Grandio, M. d., y Joan, C. (2012). Estrategias de comunicación en redes sociales. Usuarios, aplicaciones y contenidos de María del Mar Grandío y Nicolás Ojeda. Madrid: Gedisa. 
Pellegrini, S., Puente, S., Porath, W., Mujica, C. y Grassau, D. (2011). Valor Agregado Periodístico: la apuesta por la calidad de las noticias. Santiago: Ediciones UC.

Rivera Rogel, D. y Rodríguez Hidalgo, C. (2016). Periodismo ciudadano a través de Twitter. Caso de estudio terremoto de Ecuador del 16 de abril de 2016. Revista de Comunicación, (15), 198-215.

Selva-Ruíz, D. y Caro-Castaño, L. (2017). Uso de Instagram como medio de comunicación política por parte de los diputados españoles: La estrategia de humanización en la "vieja" y "nueva" política. El profesional de la información, 26(5), 903-915. doi: 10.3145/epi.2017.sep.12 